\title{
SKRINING MIOPIA PADA SISWA SEKOLAH DASAR DI KABUPATEN TEMANGGUNG
}

\author{
Nurjanah \\ Fakultas Kesehatan Masyarakat Universitas Muhammadiyah Palu

\section{MYOPIA SCREENING IN ELEMENTARY STUDENT AT TEMANGGUNG DISTRICT}

\begin{abstract}
Background: Myopia is a type of refractive error which causes visual impairment. Early detection in schoolaged children is important to prevent. Permanent visual impairment. The purpose of this study is to determine the prevalence, and risk factors, myopia in elementary student at Temanggung District.

Method: A cross-sectional analytic study design was used. The target population for screening was students from $4^{\text {th }}-6^{\text {th }}$ grade attending schools in the Temanggung and Ngadirejo sub-districts (three schools per subdistrict). Distant visual acuity was tested by trained staff using Snellen charts. Risk factors were collected by structured questionnaire, completed by parents. Univariat and bivariat analysis were performed to calculate odds ratio and multivariate analysis by logistic regression.

Results: There were 477 respondents: 51\% male and 49\% female. Age ranged between 9-15 years. The prevalence of myopia was 15\% (95\% CI: 0.11-0.17). Myopia was more common in females and children from Ngadirejo (a rural area). Bivariat analysis indicated that risk factors related to myopia are genetic, with OR=2.41 (95\%CI: 1.29-4.38) p-value 0.002, duration of television/computer game use with OR=2.08 (95\%CI: 1.17-3.79) p-value 0.007, reading distance with OR=1.83 (95\%CI: 1.04-3.22) $p$-value 0.034 and body position while reading with $\mathrm{OR}=2.46(95 \% \mathrm{CI}: 1.26-4.68)$ p-value 0.003 . Multivariate analysis identified genetic factors as the main risk factors for myopia (OR=2.23; 95\% CI: 1,23-4,02).

Conclusion: Prevalence of myopia at Temanggung District is high enough. Genetic factor was identified as the main risk factor. Myopia screening should be performed routinely to prevent permanent visual impairment. Children with a family history of myopia should be limited in near-work activity.
\end{abstract}

Keywords: Myopia, prevalence, risk factors

\begin{abstract}
ABSTRAK
Latar Belakang: Miopia adalah satu kelainan refraksi yang menyebabkan gangguan penglihatan. Deteksi dini pada anak usia sekolah sangat diperlukan untuk mencegah gangguan penglihatan permanen. Penelitian ini bertujuan untuk mengetahui prevalensi dan faktor risiko miopia pada siswa sekolah dasar di Kabupaten Temanggung.

Metode: Jenis penelitian adalah observasional analitik dengan desain cross sectional study. Skrining dilakukan terhadap siswa kelas 4-6 di Kecamatan Temanggung dan Ngadirejo (dipilih 3 sekolah per kecamatan). Pengukuran visus dilakukan oleh petugas puskesmas yang terlatih menggunakan kartu snellen. Data mengenai faktor risiko diperoleh melalui kuesioner yang diisi oleh orang tua siswa. Data dianalisis secara univariat, bivariat dan multivariat.

Hasil Penelitian: Terdapat 477 siswa yang diperiksa, 50,9\% laki-laki dan 49,1\% perempuan. Rentang umur antara 9-15 tahun. Prevalensi miopia sebesar 14,7\% (95\% CI: 0,11-0,17). Prevalensi miopia lebih banyak ditemukan pada siswa perempuan $(17,5 \%)$, berasal dari Kecamatan Ngadirejo $(17,3 \%)$ dan sedang duduk di kelas $6(23,1 \%)$. Hasil uji bivariat menunjukkan faktor risiko yang berhubungan dengan miopia adalah riwayat genetik (OR=2.41, 95\% CI: 1.29-4.38) p-value 0.002, lama menonton televisi dan/atau bermain game $(\mathrm{OR}=2.08,95 \% \mathrm{CI}: 1.17-3.79) \mathrm{p}$-value 0.007 , jarak membaca $(\mathrm{OR}=1.83,95 \% \mathrm{CI}: 1.04-3.22) \mathrm{p}$-value 0.034 dan posisi saat membaca $(\mathrm{OR}=2.46,95 \% \mathrm{CI}$ : $1.26-4.68) \mathrm{p}$-value 0.003 . Analisis multivariat menunjukkan bahwa riwayat genetik merupakan faktor risiko utama penyebab miopia $(\mathrm{OR}=2.23 ; 95 \% \mathrm{CI} ; 1,23-4,02)$.

Kesimpulan: Prevalensi miopia pada siswa sekolah dasar di Kabupaten Temanggung cukup tinggi. Riwayat genetik merupakan faktor risiko utama miopia. Disarankan agar melakukan skrining secara rutin untuk mencegah gangguan penglihatan permanen. Anak dengan riwayat genetik miopia harus dibatasi dalam melakukan aktivitas melihat dekat.
\end{abstract}

Kata Kunci: Miopia, prevalensi, faktor risiko

Alamat Koresponding: Nurjanah, Fakultas Kesehatan Masyarakat Universitas Muhammadiyah Palu, Jalan Hang Tuah No.114, email: andarwatolanrain@gmail.com 


\section{PENDAHULUAN}

Miopia atau lebih dikenal dengan rabun jauh merupakan salah satu jenis kelainan refraksi yang memiliki prevalensi cukup tinggi. ${ }^{1}$ World Health Organization (WHO) memperkirakan terdapat 27\% (1.893 juta) penduduk di seluruh dunia menderita miopia pada tahun 2010, sekitar $90 \%$ diantaranya berada di negara berkembang. ${ }^{2,3}$ Setiap tahun prevalensi miopia terus meningkat. Selain itu, diketahui bahwa usia awal seseorang mengalami miopia menjadi semakin muda., ${ }^{4,5}$

Hasil studi menunjukkan bahwa Asia Timur merupakan wilayah dengan prevalensi miopia tertinggi (China, Jepang, Korea dan Singapore memiliki prevalensi sekitar 50\%), kemudian diikuti Australia, Eropa, Amerika Utara dan Amerika Selatan. ${ }^{2}$ Sementara itu, prevalensi gangguan ketajaman penglihatan pada penduduk berusia $\geq 6$ tahun di Indonesia sebesar $0,9 \%$. Wilayah dengan prevalensi tertinggi ditemukan di Lampung (1,7\%), Nusa Tenggara Timur dan Kalimantan Barat (masing-masing 1,6\%). Sementara provinsi dengan prevalensi gangguan penglihatan terendah adalah DI Yogyakarta $(0,3 \%)$ diikuti oleh Papua Barat dan Papua (masing-masing $0,4 \%)^{6}$

Secara umum terdapat tiga faktor utama penyebab miopia, yaitu kelainan bawaan pada mata, faktor lingkungan dan genetic. ${ }^{2}$ Hasil penelitian Abimanyu menunjukkan bahwa jarak dan posisi tubuh saat membaca, jarak menonton televisi dan faktor genetik merupakan faktor risiko miopia pada siswa sekolah dasar di Kabupaten Tanggamus. ${ }^{7}$ Penelitian serupa yang dilakukan oleh Purwanto juga menunjukkan bahwa faktor lingkungan dan kebiasaan anak memiliki hubungan yang bermakna terhadap kejadian myopia. ${ }^{1}$

Saat ini, belum tersedia data yang akurat mengenai prevalensi dan faktor penyebab miopia di Kabupaten Temanggung, khususnya pada siswa sekolah dasar yang merupakan salah satu kelompok berisiko. Hal tersebut penting untuk diketahui sebagai dasar bagi perbaikan program kesehatan pada siswa sekolah di Kabupaten Temanggung. Selain itu, deteksi dini melalui skriningjuga sangat diperlukan untuk mencegah terjadinya gangguan penglihatan permanen dan komplikasi berat yang dapat berdampak pada depan anak. Tujuan dari penelitian ini adalah untuk mengetahui prevalensi dan faktor risiko miopia pada siswa sekolah dasar di Kabupaten Temanggung.

\section{METODE}

Jenis penelitian adalah observasional analitik dengan desain cross sectional study. Sampel dalam penelitian ini dipilih menggunakan multistage random sampling. ${ }^{8}$ Tahap pertama adalah penentuan sampel kecamatan yang dianggap mewakili karakteristik wilayah di Kabupaten Temanggung, yaitu semi perkotaan dan pedesaan. Dari hasil random, terpilih Kecamatan Temanggung (sampel wilayah semi perkotaan) dan Kecamatan Ngadirejo (sampel wilayah pedesaan).Selanjutnya dari setiap kecamatan dipilih masing-masing 3 sekolah dasar secara acak (total 6 sekolah) yang menjadi lokasi penelitian. Adapun subjek penelitian adalah siswa kelas 4, 5 dan 6 di sekolah tersebut.

Pengukuran visus dilakukan oleh petugas puskesmas menggunakan kartu Snellen. Faktor risiko genetik, lama menonton televisi dan/atau bermain game, jarak saat membaca dan posisi tubuh saat membaca diperoleh melalui kuesioner yang diisi oleh orangtua siswa. Kategori miopia yang digunakan dalam penelitian ini adalah nilai visus dibawah $5 / 5$ pada salah satu atau kedua mata berdasarkan hasil pemeriksaan dengan kartu Snellen. Data dianalisis secara univariat untuk melihat distribusi frekuensi dari masing-masing variabel, uji bivariat untuk menghitung nilai odds ratio dan uji multivariat menggunakan regresi logistik.

\section{HASIL PENELITIAN}


Terdapat 518 siswa dari 6 sekolah yang menjadi target skrining, namun hanya 477 siswa (92\%) yang diperiksa karena 29 siswa (6\%) menolak berpartisipasi dan 12 siswa lainnya $(2 \%)$ tidak hadir saat pemeriksaan dilakukan. Rata-rata umur siswa adalah $10,8 \pm 1,15$ tahun. Rasio antara siswa laki-laki dan perempuan hampir sama, yaitu 50,9\% laki-laki dan 49,1\% perempuan. Berdasarkan lokasi sekolah, terlihat bahwa jumlah siswa yang berasal dari Kecamatan Temanggung sebesar $\quad 49,1 \%$ sementara $50,9 \%$ lainnya berasal dari Kecamatan Ngadirejo. Proporsi siswa pada kelas 4, 5 dan 6 juga tidak berbeda jauh, masing-masing $34,4 \%, 32,1 \%$ dan $33,5 \%$.

Tabel 1.

Karakteristik Subjek Skrining Kelainan Refraksi Miopia pada Siswa Sekolah Dasar

\begin{tabular}{lcc}
\hline \multicolumn{1}{c}{ Variabel } & $\begin{array}{c}\text { Jumlah } \\
(\mathbf{n = 4 7 7})\end{array}$ & $\begin{array}{c}\text { Persentase } \\
(\mathbf{\%})\end{array}$ \\
\hline $\begin{array}{l}\text { Umur }(\text { tahun) } \\
\text { (mean+SD) }\end{array}$ & & $10,8 \pm 1,15$ \\
\hline Jenis Kelamin & & \\
Laki-laki & 243 & 50,9 \\
Perempuan & 234 & 49,1 \\
\hline Lokasi Sekolah & & \\
Kecamatan Temanggung & 234 & 49,1 \\
Kecamatan Ngadirejo & 243 & 50,9 \\
\hline Kelas & & \\
4 & 164 & 34,4 \\
5 & 153 & 32,1 \\
6 & 160 & 33,5 \\
\hline
\end{tabular}

Berdasarkan hasil penelitian, diketahui bahwa persentase siswa berdasarkan nilai visus pada mata kanan dan kiri tidak menunjukkan perbedaan yang cukup besar. Pada mata kanan, terdapat 421 siswa $(88,3 \%)$ memiliki nilai visus $5 / 5$ (normal) dan persentase terkecil berada nilai visus $4 / 5$ dan $5 / 24$, masing-masing sebesar 0,2\%. Demikian juga untuk mata kiri, terdapat 414 siswa $(86,8 \%)$ siswa memiliki visus normal, sementara nilai visus dengan persentasi terkecil adalah 4/5 dan 5/36, masing-masing sebesar $0,2 \%$.

Berdasarkan hasil uji statistik secara bivariat, diketahui bahwa riwayat genetik
Tabel 2.

Distribusi Nilai Visus Berdasarkan Hasil Skrining Kelainan Refraksi Miopia pada Siswa Sekolah Dasar

\begin{tabular}{ccccc}
\hline \multirow{2}{*}{ Nilai Visus } & \multicolumn{2}{c}{ Mata Kanan } & \multicolumn{2}{c}{ Mata Kiri } \\
\cline { 2 - 5 } & n & \% & n & \% \\
\hline $5 / 5$ & 421 & 88, & 414 & 86,8 \\
& & 3 & & \\
$4 / 5$ & 1 & 0,2 & 1 & 0,2 \\
$5 / 6$ & 15 & 3,1 & 18 & 3,8 \\
$5 / 8$ & 10 & 2,1 & 10 & 2,1 \\
$5 / 9$ & 5 & 1,0 & 6 & 1,3 \\
$5 / 12$ & 9 & 1,9 & 9 & 1,9 \\
$5 / 15$ & 6 & 1,3 & 6 & 1,3 \\
$5 / 18$ & 7 & 1,5 & 8 & 1,7 \\
$5 / 24$ & 1 & 0,2 & 4 & 0,8 \\
$5 / 36$ & 2 & 0,4 & 1 & 0,2 \\
\hline Total & $\mathbf{4 7 7}$ & $\mathbf{1 0 0}$ & $\mathbf{4 7 7}$ & $\mathbf{1 0 0}$ \\
\hline
\end{tabular}

Adapun prevalensi miopia yang didapatkan dalam penelitian ini adalah $14,7 \%$ $(95 \% \quad \mathrm{CI}=11,4-17,8) . \quad$ Berdasarkan jenis kelamin, prevalensi miopia lebih tinggi pada perempuan, yaitu sebesar $17,5 \%$ sedangkan pada laki-laki hanya $11,9 \%$.Berdasarkan lokasi sekolah, prevalensi miopia di Kecamatan Ngadirejo lebih tinggi (17,3\%) dibandingkan Kecamatan temanggung (12\%). Sementara itu berdasarkan tingkatan kelas, prevalensi miopia tertinggi terdapat pada siswa kelas 6 yaitu sebesar $23,1 \%$ dan yang paling rendah berada di kelas 4 sebesar 6,7\%.

Tabel 3.

Prevalensi Miopia Berdasarkan Karakteristik Siswa Sekolah Dasar

\begin{tabular}{cccc}
\hline Variabel & $\begin{array}{c}\text { Jumlah } \\
\text { siswa } \\
(\mathbf{n = 4 7 7})\end{array}$ & $\begin{array}{c}\text { Jumlah } \\
\text { Siswa } \\
\text { Miopia } \\
(\mathbf{n = 7 0})\end{array}$ & $\begin{array}{c}\text { Prevalensi } \\
(\%)\end{array}$ \\
\hline $\begin{array}{c}\text { Jenis Kelamin } \\
\text { Laki-laki }\end{array}$ & 243 & 29 & 11,9 \\
Perempuan & 234 & 41 & 17,5 \\
\hline Lokasi Sekolah & & & \\
Kecamatan & 234 & 28 & 12,0 \\
Temanggung & 243 & 42 & 17,3 \\
Kecamatan & & & \\
Ngadirejo & & & \\
\hline Kelas & & & 6,7 \\
4 & 164 & 11 & 14,4 \\
5 & 153 & 22 & 23,1 \\
\hline 6 & 160 & 37 & \\
\hline
\end{tabular}

memiliki nilai OR sebesar 2,41. Sehingga dapat dikatakan bahwa siswa yang memiliki 
riwayat genetik miopia dari orang tuanya memiliki risiko 2,41 kali lebih besar untuk menderita miopia dibandingkan siswa yang tidak memiliki riwayat miopia. Variabel lama menonton televisi dan/atau bermain game memiliki $\mathrm{OR}=2,08$. Artinya, siswa yang memiliki kebiasaan menonton televisi dan/atau bermain game $\geq 3$ jam sehari berisiko 2,08 kali lebih besar untuk menderita miopia dibandingkan siswa yang hanya menghabiskan $<3$ jam sehari untuk menonton televisi dan/atau bermain game.

Adapun nilai OR untuk variabel jarak saat membaca adalah 1,83. Hal ini menunjukkan bahwa siswa yang sering membaca pada jarak $<30 \mathrm{~cm}$ memiliki risiko 1,83 kali lebih besar untuk menderita miopia dibandingkan siswa yang membaca pada jarak $\geq 30 \mathrm{~cm}$. Untuk variabel posisi tubuh saat membaca memiliki nilai OR sebesar 2,46. Artinya bahwa siswa yang memiliki kebiasaan membaca dalam posisi berbaring berisiko 2,46 kali lebih besar untuk menderita miopia dibandingkan siswa yang membaca dalam posisi duduk.

Selanjutnya dilakukan uji multivariat terhadap 4 faktor risiko tersebut dan diperoleh hasil bahwa 3 dari 4 variabel yang ada merupakan faktor risiko terjadinya miopia dan bermakna secara statistik ( $p$-value $<0,05)$ yaitu variabel riwayat genetik ( $\mathrm{OR}=2,23)$, lama menonton televisi dan/atau bermain game $(\mathrm{OR}=1,80)$ dan posisi tubuh saat membaca $(\mathrm{OR}=1,98)$. Adapun variabel jarak saat membaca memiliki nilai OR 1,51 namun hal tersebut tidak bermakna secara statistik ( $p$ value $>0,05)$.

\section{Tabel 4.}

\section{Analisis Bivariat dan Multivariat Faktor Risiko Miopia pada Siswa Sekolah Dasar di Kabupaten Temanggung}

\begin{tabular}{|c|c|c|c|c|c|c|}
\hline \multirow[b]{2}{*}{ Faktor Risiko } & \multirow[b]{2}{*}{ Miopia } & \multirow[b]{2}{*}{ Normal } & \multicolumn{2}{|c|}{ Unadjasted } & \multicolumn{2}{|c|}{ Adjusted } \\
\hline & & & $\begin{array}{c}\text { OR } \\
\text { CI }(95 \%)\end{array}$ & P-Value & $\begin{array}{c}\text { OR } \\
\text { CI }(95 \%)\end{array}$ & P-Value \\
\hline \multicolumn{7}{|l|}{ Riwayat Genetik } \\
\hline Ada & 22 & 65 & 2,41 & 0,002 & 2,23 & 0,007 \\
\hline Tidak ada & 48 & 31 & $(1,29-4,38)$ & & $(1,23-4,02)$ & \\
\hline \multicolumn{7}{|c|}{$\begin{array}{l}\text { Lama menonton } \\
\text { televisidan/atau bermain game }\end{array}$} \\
\hline $\begin{array}{l}\text { (jam/hari) } \\
\quad \geq 3 \\
\quad<3\end{array}$ & $\begin{array}{l}49 \\
21\end{array}$ & $\begin{array}{l}215 \\
192\end{array}$ & $\begin{array}{c}2,08 \\
(1,17-3,79)\end{array}$ & 0,007 & $\begin{array}{c}1,80 \\
(1,02-3,18)\end{array}$ & 0,04 \\
\hline \multicolumn{7}{|l|}{ Jarak saat membaca $(\mathrm{cm})$} \\
\hline $\begin{array}{l}<30 \\
>30\end{array}$ & $\begin{array}{l}21 \\
49\end{array}$ & $\begin{array}{r}77 \\
330\end{array}$ & $\begin{array}{c}1,83 \\
(1,04-3,22)\end{array}$ & 0,034 & $\begin{array}{c}1,51 \\
(0,83-2,74)\end{array}$ & 0,175 \\
\hline \multicolumn{7}{|c|}{ Posisi tubuh saat membaca } \\
\hline $\begin{array}{l}\text { Berbaring } \\
\text { Duduk }\end{array}$ & $\begin{array}{l}18 \\
52\end{array}$ & $\begin{array}{r}30 \\
356\end{array}$ & $\begin{array}{c}2,46 \\
(1,25-4,68)\end{array}$ & 0,003 & $\begin{array}{c}1,98 \\
(1,03-3,77)\end{array}$ & 0,038 \\
\hline
\end{tabular}

\section{PEMBAHASAN}

Hasil skrining menunjukkan bahwa prevalensi kelainan refraksi miopia pada siswa SD di Kabupaten Temanggung adalah sebesar $14,7 \%$. Prevalensi ini lebih tinggi dibandingkan dengan prevalensi miopia di Kota Makassar yang hanya sebesar 2,7\% dan Malaysia 5\%. ${ }^{9,10}$ Namun hasil tersebut masih tergolong rendah jika dibandingkan dengan hasil skrining serupa pada siswa SD di Jakarta yang mencapai $51,9 \% .{ }^{11}$ Perbedaan prevalensi dengan penelitian sebelumnya dapat terjadi karena beberapa hal, diantaranya pemilihan sampel yang beragam, jumlah sasaran yang di skrining, metode pemeriksaan dan cut off point yang digunakan dalam pengkategorian satus miopia, status sosial ekonomi, serta 
perbedaan kondisi geografis pada setiap wilayah penelitian.

Tingginya prevalensi miopia pada siswa SD di Kabupaten Temanggung bisa berdampak pada terganggunya proses belajar siswa tersebut karena dapat menyebabkan menurunnya performa siswa di sekolah, hilangnya ketertarikan untuk belajar bahkan bisa berdampak pada masalah perilaku seperti ketidakmampuan dalam menerima pelajaran dan gangguan dalam perkembangan bacatulis. Bila tidak segera mendapatkan pengobatan, akan memperparah gangguan penglihatan dan berdampak buruk pada proses belajarnya. ${ }^{12}$

Hasil penelitian menunjukkan bahwa riwayat genetik merupakan faktor risiko miopia pada siswa SD di Kabupaten Temanggung. Hal ini sesuai dengan penelitian Fatika dan Abiemanyu yang menunjukkan bahwa anak yang memiliki riwayat miopia memiliki risiko yang lebih besar untuk menderita miopia dibandingkan anak yang tidak memiliki riwayat myopia. ${ }^{7,13}$ Penelitian lain yang dilakukan oleh Sarwanto dan Anwar di Surabaya juga menunjukkan bahwa 43,9\% miopia disebabkan oleh faktor keturunan dan kebiasaan membaca. ${ }^{14}$ American Academy of Ophthalmology juga menegaskan bahwa miopia yang terjadi pada masa anak-anak usia 7-16 tahun atau disebut juvenile myopia, salah satunya disebabkan karena adanya riwayat miopia pada keluarga. ${ }^{15}$ Selain faktor genetik, terdapat faktor lain yang turut berperan terhadap kejadian miopia pada anak, yaitu perilaku atau kebiasaan orang tua. Menurut Guggenheim, orang tua dengan tingkat pendidikan tinggi umumnya suka membaca. Kebiasaan inilah yang akan menurun kepada anak-anaknya sehingga risiko untuk terjadinya miopia akan semakin besar. ${ }^{16}$

Lama menonton televisi dan/atau bermain game diketahui merupakan faktor risiko terjadinya miopia. Hasil ini sejalan dengan penelitian yang dilakukan oleh Purwanto yang menunjukkan bahwa terdapat hubungan yang bermakna antara kebiasaan siswa (antara lain lama waktu baca, posisi membaca dan jarak membaca) dengan myopia. ${ }^{1}$ Penelitian serupa yang dilakukan oleh Rahimi juga menunjukkan bahwa siswa yang memiliki aktivitas melihat dekat lebih dari 3 jam per hari memiliki risiko 4 kali lebih besar untuk menderita myopia. ${ }^{17}$ Lamanya waktu yang dihabiskan untuk aktivitas melihat dekat menyebabkan upaya akomodasi yang berlebihan ketika mata mencoba untuk memfokuskan objek. Kondisi ini menyebabkan perubahan adiptif pada kekuatan pembiasan dari lensa crystalline dan beberapa sistem yang berhubungan, seperti tonus dari otot siliar menjadi hipertropi dan atropi sehingga menyebabkan seseorang menjadi myopia. ${ }^{18,19}$

Penelitian ini juga menunjukkan bahwa posisi tubuh saat membaca merupakan faktor risiko terjadinya miopia. Hal ini sejalan dengan penelitian Abiemanyu yang menyatakan bahwa anak yang terbiasa membaca dalam posisi tiduran memiliki risiko 3,59 kali lebih besar untuk menderita miopia dibanding anak yang membaca dalam posisi duduk. $^{7}$ Penelitian Purwanto juga mendapatkan bahwa terdapat hubungan yang bermakna antara kebiasaan (diantaranya posisi saat membaca) dengan miopia ${ }^{1}$.Hal ini terjadi karena pada saat membaca dalam posisi berbaring/tiduran, jarak antara mata dengan objek bacaan tidak stabil sehingga mata selalu berakomodasi. Selain itu, juga terjadi pengurangan intensitas cahaya karena objek bacaan akan membelakangi sumber cahaya sehingga mata akan lebih berakomodasi dan cepat lelah. Kondisi tersebut akan semakin parah jika kondisi pencahayaan di tempat membaca kurang baik (redup), sehingga mata akan semakin cepat merasa lelah. Hal inilah yang bisa meningkatkan risiko mata minus. ${ }^{7}$

\section{KESIMPULAN DAN SARAN}

Berdasarkan hasil penelitian, dapat disimpulkan bahwa prevalensi miopia pada siswa sekolah dasar di Kabupaten 
Temanggung sebesar $14,7 \%$. Adapun faktor risiko terjadinya miopia adalah riwayat genetik $(\mathrm{OR}=2,23)$, lama menonton televisi dan/atau bermain game $(\mathrm{OR}=1,80)$ dan posisi tubuh saat membaca $(\mathrm{OR}=1,98)$. Riwayat genetik merupakan faktor risiko utama miopia pada siswa sekolah dasar di Kabupaten Temanggung. Disarankan agar Dinas Kesehatan Kabupaten Temanggung dan pihak

\section{DAFTAR PUSTAKA}

1. Purwanto, SigitFaktor Determinan yang Berhubungan dengan Kejadian Miopia. Jurnal Ilmu Kesehatan Masyarakat. 2010. No.3, Vol.1, 162 169.http://eprints.unsri.ac.id/id/eprint/406 9

2. World Health Organization. The Impact of Myopia and High Myopia. Report of the Joint WHO-Brien Holden Vision Institute Global Scientific Meeting on Myopia. WHO. Sydney.2015.

3. World Health Organization. Visual Impairment and Blindness. 2012.http://www.who.int/mediacentre/fa ctsheets/fs282/en/\#. Diakses pada 5 Maret 2015

4. Khalaj, M. Prevalence of Refractive Errors in Primary School Children (7-15 years) of Qazvin City. European Journal of Scientific Research. 2009. No.2, Vol.28, 174-185.

5. Lin, LKK., YF, Shih., Hsiao, CK., Chen, CJ. Prevalence of Myopia in Taiwanese Schoolchildren: 1983 to 2000. Ann Academy Med Singapore. Vol.33, 27-33.

6. Kementerian Kesehatan RI. Laporan Riset Kesehatan Dasar 2013. Kemenkes. Jakarta.2013.

7. Abiemanyu, J. K. Faktor yang Berhubungan dengan Kelainan Refraksi Miopia pada Anak Sekolah Dasar di Kabupaten Tanggamus Tahun 2009/2010 [tesis]. Yogyakarta: Fakultas Kedokteran Universitas Gadjah Mada.2012.

8. Murti, Bhisma. Desain dan Ukuran Sampel Untuk Penelitian Kuantitatif dan Kualitatif fi Bidang Kesehatan.Gadjah Mada University Press: Yogyakarta.2013.

9. Launardo, A. V., Afifudin, A., Syamsu, N., \& Taufik, R. Kelainan Refraksi pada puskesmas melaksanakan skrining miopia secara rutin untuk mencegah gangguan penglihatan permanen. Orang tua diharapkan dapat membatasi anak dengan riwayat genetik miopia untuk melakukan aktivitas melihat dekat dalam waktu yang cukup lama dan diarahkan agar memiliki kebiasaan membaca pada posisi duduk.

Anak Usia 3-6 Tahun di Kecamatan Tallo Kota Makassar [tesis]. Makassar: Universitas Hasanuddin. 2010

10. Premsenthil, M., Manju, R., Thanaraj, A., Alwi, S., Abdul, S., \& Kah, T. A. The screening of visual impairment among preschool children in an urban population in Malaysia; the Kuching pediatric eye study: a cross sectional study. BMC Ophthalmology. 2013. No.13, Vol.16, 15. http://www.biomedcentral.com/14712415/13/16

11. Fachrian, D., Rahayu, A. B., Naseh, A. J., Rerung, N. E. T., Pramesti, M., Sari, E. A., Suarthana, E. Prevalensi Kelainan Tajam Penglihatan pada Pelajar SD " $X$ ” Jatinegara Jakarta Timur. Majalah Kedokteran Indonesia. 2009, No.6, Vol.59, 261-264.

12. Hong, C. L., \& Press, L. J. Visual Factors in Childhood Behavioral Disorders. California Optometry. 2009. No.4, Vol.36, 46-54. http://www.pressvision.com/pdf/hong_pr ess.pdf

13. Fatika. Hubungan Faktor Keturunan, Lamanya Bekerja Jarak Dekat dengan Miopia pada Mahasiswa FK USU [skripsi]. Medan: Universitas Sumatera Utara. 2009.

14. Sarwanto\& Anwar, Syaiful. Hubungan Karakteristik, Pengetahuan, Sikap dan Perilaku Ibu-ibu Anak SD Kelas 6 Tentang Kelainan Refraksi (Studi Kasus di SD Kemayoran I dan II Kecamatan Krembangan Surabaya. Buletin Penelitian Kesehatan. 2007.No.1, Vol.35, 15-24.

http://ejournal.litbang.depkes.go.id/index .php/BPK/article/viewFile/2134/1144

15. American Academy of Ophthalmology. Optic, Refraction and Contact Lens. 
Basic and Clinical Science Course Section 3. American Academy of Ophthalmology: San Francisco.2004.

16. Guggenheim. Correlation in Refractive Errors Between Siblings in The Singapore Cohort Study of Risk Factor for Myopia. British Journal of Ophthalmology. 2007. No.6, Vol.91, 781-784

17. Rahimi, Martga Bella., Yanwirasti.,sayuti, Kemala. Faktor-faktor yang Memengaruhi Insiden Miopia pada Siswa Sekolah Menengah Atas di Kota
Padang. Jurnal Kesehatan Andalas. 2015.No.3, Vol.4, 901-907.

18. Saminan. Efek Bekerja dalam Jarak Dekat terhadap Kejadian Miopia. Jurnal Kedokteran Syiah Kuala. 2013. No.3, Vol.13, 187-191. http:// www.jurnal. unsyiah.ac.id /JKS/ article/ viewFile/3288/3094.

19. Jenny, M. Role of Near Work in Myopia: Findings in a Sample of Australian School Children. Investigative Ophthalmology \& Visual Science. 2008. No.7, Vol.49, 2903-2910. DOI:10.1167/iovs.07-0804. 